\title{
Prevalence of Multimorbidity Among Adults Seen in Family Practice
}

\author{
Martin Fortin, MD, MSc, CMFC \\ Gina Bravo, $P b D^{2}$ \\ Catherine Hudon, MD, CMFC ${ }^{1}$ \\ Alain Vanasse, $M D, P b D, C M F C^{1}$ \\ Lise Lapointe, $M A^{1}$ \\ 'Department of Family Medicine, \\ Sherbrooke University, Québec, Canada \\ ${ }^{2}$ Department of Community Health Sciences, \\ Sherbrooke University, Québec, Canada
}

Conflicts of interest: none reported

\section{CORRESPONDING AUTHOR}

Martin Fortin, MD, MSc, CMFC

Unité de Médecine de Famille

305 St-Vallier

Chicoutimi, Québec

G7H $5 \mathrm{H} 6$

martinfortin@videotron.ca

\begin{abstract}
PURPOSE There are few valid data that describe the extent of multimorbidity in primary care patients. The purpose of this study was to estimate its prevalence in family practice patients by counting the number of chronic medical conditions and using a measure that considers the severity of these conditions, the Cumulative Illness Rating Scale (CIRS).
\end{abstract}

METHODS The study was carried out in the Saguenay region (Québec, Canada) in 2003. The participation of adult patients from 21 family physicians was solicited during consecutive consultation periods. A research nurse reviewed medical records and extracted the data regarding chronic illnesses. For each chronic condition, a severity rating was determined in accordance with the CIRS scoring guidelines.

RESULTS The sample consisted of 320 men and 660 women. Overall, 9 of 10 patients had more than 1 chronic condition. The prevalence of having 2 or more medical conditions in the 18- to 44-year, 45- to 64-year, and 65-year and older age-groups was, respectively, 68\%, 95\%, and 99\% among women and $72 \%$, $89 \%$, and $97 \%$ among men. The mean number of conditions and mean CIRS score also increased significantly with age.

CONCLUSIONS Whether measured by simply counting the number of conditions or using the CIRS, the prevalence of multimorbidity is quite high and increases significantly with age in both men and women. Patients with multimorbidity seen in family practice represent the rule rather than the exception.

Ann Fam Med 2005;3:223-228. DOI: 10.1370/afm.272.

\section{INTRODUCTION}

$\mathrm{M}$ ultimorbidity may be defined as the simultaneous occurrence of several medical conditions in the same person. ${ }^{1}$ Although family physicians care for such patients on a daily basis, there are few valid data that describe the extent of the multimorbidity phenomenon. ${ }^{2}$ It is estimated that 57 million Americans had multiple chronic conditions in 2000 and that this number will rise to 81 million by $2020 .^{3}$

A few studies have estimated the prevalence of multimorbidity in Europe ${ }^{4,5}$ the Middle East ${ }^{6}$ the United States, ${ }^{7-9}$ and Canada. ${ }^{10}$ Table 1 summarizes the prevalence data found in the literature. There are, however major differences in the sources and results of these studies. ${ }^{4-10}$ The data were obtained from various surveys ${ }_{,}^{8-10}$ administrative databases, ${ }_{1}^{7}$ or computerized networks of family practices. ${ }^{4,5}$ None of these reports includes prevalence data obtained from a review of medical records, although some have suggested that this strategy is the best way to collect information about medical diagnoses. Furthermore, almost one half the studies were limited to elderly populations. In these studies, multimorbidity was defined as 2 or more chronic medical conditions, and the measure was a simple count of such conditions. As the diagnoses taken into account differed, the total number of chronic conditions reported widely varied.

When addressing the problem of multimorbidity, the first difficulty that arises is the lack of a clear definition that also captures the clinical burden. 


\section{Table 1. Published Data on Multimorbidity}

\begin{tabular}{|c|c|c|c|c|}
\hline Author & $\begin{array}{c}\text { Country } \\
\text { Data Collection } \\
\text { Year }\end{array}$ & Context & $\begin{array}{l}\text { Prevalence* of } \\
\text { Multimorbidity } \\
\text { by Age-Group }\end{array}$ & $\begin{array}{c}\text { Chronic Health } \\
\text { Problems per } \\
\text { Person } \\
\text { Average No. }\end{array}$ \\
\hline Guralnik et $\left.a\right|^{8}$ & $\begin{array}{l}\text { United States } \\
\text { before } 1989\end{array}$ & $\begin{array}{l}\text { General } \\
\text { population } \\
\text { (survey) }\end{array}$ & $\begin{array}{r}60-69 \text { y: } 35 \\
70-79 \text { y: } 47 \\
80+y: 53\end{array}$ & - \\
\hline $\begin{array}{l}\text { Metsemakers } \\
\text { et } \mathrm{al}^{5}\end{array}$ & $\begin{array}{l}\text { Netherlands, } \\
1990\end{array}$ & $\begin{array}{l}\text { Family } \\
\text { medicine } \\
\text { registry }\end{array}$ & - & $\begin{array}{l}25-44 \text { y: } 2.4,2.9^{+} \\
45-64 \text { y: } 3.8,4.3^{+} \\
65-74 \text { y: } 5.0,5.2^{+} \\
75+y: 5.7,6.2^{+}\end{array}$ \\
\hline Hoffman et al ${ }^{9}$ & $\begin{array}{l}\text { United States, } \\
1987\end{array}$ & $\begin{array}{l}\text { General } \\
\text { population } \\
\text { (survey) }\end{array}$ & $\begin{array}{r}18-44 \text { y: } 28.4^{\ddagger} \\
45-64 \text { y: } 51.0^{\ddagger} \\
65+y: 69.2^{\ddagger}\end{array}$ & - \\
\hline $\begin{array}{l}\text { Van den Akker } \\
\text { et } \mathrm{al}^{4}\end{array}$ & $\begin{array}{l}\text { Netherlands, } \\
1994\end{array}$ & $\begin{array}{l}\text { Family } \\
\text { medicine } \\
\text { registry }\end{array}$ & $\begin{array}{r}0-19 \text { y: } 10.0 \\
20-39 \text { y: } 17.4 \\
40-59 \text { y: } 34.7 \\
60-79 \text { y: } 63.1 \\
80+y: 78.2\end{array}$ & $\begin{array}{r}40-59 y: 1.3 \\
60-79 y: 2.5 \\
80+y: 3.5\end{array}$ \\
\hline Daveluy ${ }^{10}$ & $\begin{array}{c}\text { Canada (Quebec), } \\
1998\end{array}$ & $\begin{array}{l}\text { General } \\
\text { population } \\
\text { (survey) }\end{array}$ & $\begin{array}{r}25-44 y: 27.7 \\
45-64 y: 40.2 \\
65+y: 63.4\end{array}$ & - \\
\hline Fuchs ${ }^{6}$ & $\begin{array}{c}\text { Israel, } \\
\text { 1989-1992 }\end{array}$ & $\begin{array}{l}\text { General } \\
\text { population } \\
\text { (survey) }\end{array}$ & $75+y: 64.0$ & 2.2 \\
\hline Wolff 7 & $\begin{array}{c}\text { United States, } \\
1999\end{array}$ & Medicare & $\begin{array}{r}65-69 \text { y: } 53.9 \\
70-74 \text { y: } 63.1 \\
75-79 \text { y: } 68.8 \\
80-84 \text { y: } 72.5 \\
85+y: 72.8\end{array}$ & 2.3 \\
\hline This study & $\begin{array}{l}\text { Canada, } \\
2003\end{array}$ & $\begin{array}{l}\text { Family } \\
\text { medicine }\end{array}$ & $\begin{array}{r}18-44 \text { y: } 69.3 \\
45-64 \text { y: } 92.8 \\
65+y: 98.7\end{array}$ & $\begin{array}{r}18-14 y: 2.8 \\
45-64 y: 4.6 \\
65+y: 6.5\end{array}$ \\
\hline
\end{tabular}

improving the overall quality of care for these particular patients.

\section{METHODS}

\section{Study Region}

The study was carried out in the Saguenay region of the Province of Québec in 2003. This region has a population of approximately 150,000 living in 1 major city and several smaller centers. The socioeconomic status (SES) of residents is comparable to that of those in the rest of Canada, except for a higher unemployment rate $(12 \%$ vs $8 \%$ in 2001). Other characteristics, including the age distribution, education level, and median household income, are similar. ${ }^{14}$

The Saguenay region has about 130 general practitioners, nearly $80 \%$ of whom have a general practice and work in a private doctors' office or an institution. The ratio of general practitioners to patients $(8.7$ per 10,000$)$ is a little less than the average 9.5 for Canada. In terms of specialized care, the Saguenay region is similar to the Canadian average, with 9.0 medical specialists per 10,000 people. ${ }^{15}$ This figure represents only $60 \%$ of its estimated staffing needs. A regional hospital mainly

Although a conceptual framework for measuring multimorbidity has yet to be proposed, it seems obvious that such a measure should include a means of evaluating the severity of the medical conditions. One could readily agree that a patient suffering concurrently from hypothyroidism and eczema does not have the same burden of illness as does a patient with asthma and diabetes; therefore, simply counting the number of conditions seems to be too restrictive. Using a comorbidity index that takes the severity of the conditions into account seems preferable. Among current comorbidity indices, the Cumulative Illness Rating Scale (CIRS) ${ }^{11}$ is one of the best suited to the primary care context. ${ }^{12,13}$

The purpose of this study was to estimate the prevalence of multimorbidity in family practice patients by counting the number of medical conditions and using a measure that considers their severity. It is part of a broader research program aimed at increasing our understanding of the consequences of multimorbidity and provides specialized services and 2 smaller hospitals serve the local population.

\section{Physician Eligibility and Characteristics}

We used a 2-level survey plan. The first level consisted of the population of family physicians contacted. The second level consisted of the patients of the physicians recruited.

A total of 119 family physicians were considered eligible and contacted; 86 replied and 27 of them volunteered to participate. The eligibility criteria were (1) the physician had to have a general practice in a doctors' office or an institution with easily accessible medical records, and (2) this practice had to include adult patients of all ages

The final sample consisted of 21 physicians after 6 dropped out before data collection began (pregnancy, moved, or withdrew consent). This sample of 16 physicians in private practice and 5 working in institutions 


\section{Table 2. Characteristics of Physicians}

\begin{tabular}{lccc}
\hline Characteristics & $\begin{array}{c}\text { Participants } \\
\mathbf{n}=\mathbf{2 1}\end{array}$ & $\begin{array}{c}\text { Nonparticipants } \\
\mathbf{n}=\mathbf{9 8}\end{array}$ & P Value \\
\hline Male, \% & 57.1 & 50.0 & $.63^{*}$ \\
Private practice, \% & 76.2 & 84.7 & $.35^{*}$ \\
Urban area, \% & 90.5 & 81.6 & $.52^{*}$ \\
Years in practice, No. & 17.4 & 16.6 & $.30^{\dagger}$ \\
\hline * Fisher's exact test. & & \\
† Student $t$ test. & & \\
\hline
\end{tabular}

to determine a severity score for each domain. This scoring system is flexible and simple, making it easy to use. Although a scoring manual for the CIRS-G is available, the CIRS criteria apply equally well to an adult population. ${ }^{15}$ The CIRS has undergone several validation studies. ${ }^{11,18,19}$

Nurses' training consisted of a 1-day program that included instruction in chart reviewing using data extraction materials especially prepared for this study. The main investigator also made regular contact with the nursing staff during the

was considered representative of the practice setting. Table 2 summarizes their characteristics. The profile of physicians not participating was drawn from administrative data from the College of Physicians of Québec and did not differ significantly from that of the participants.

The Sagamie Hospital Research Ethics Board approved this study.

\section{Patient Recruitment and Data Collection}

The patients were recruited during consecutive consultation periods. The recruitment was under the responsibility of the clinic's staff, who were instructed to recruit all patients visiting for appointments during a short period of time (up to a few weeks). After the clinic's staff had described the study, the adult patients (18 years and older) were asked to sign a consent form giving permission to access their medical records. Patients who lacked decision-making capacity or could not read the consent form were not asked to participate. Pregnant women were also excluded. The study coordinator made monitoring telephone calls to ensure good participation by the staff.

Next, 1 of 2 trained research nurses reviewed the medical records and completed the data extraction grid, including the list of chronic diseases diagnosed and medical history. A severity score was assigned for each diagnosis identified. Any ambiguities in scoring severity were clarified with the attending physician.

Diagnoses of chronic medical conditions were compiled and counted based on the World Health Organization's (WHO) definition of chronic conditions, ie, "health problems that require ongoing management over a period of years or decades." ${ }^{16}$ From the data collected, we also determined a comorbidity index using the CIRS. As an additional domain made it more comprehensive than the original scale described by Linn et al, ${ }^{11}$ we used the geriatric version modified by Miller and Towers (CIRS-G). ${ }^{17}$

\section{Scoring and Validation}

The CIRS uses a scoring system that includes 14 anatomical domains; a scale ranging from 0 (no condition in this domain) to 4 (extremely serious condition) is used study to monitor their work. Instructions for the scoring severity were very simple, according to the work by Miller and Towers. ${ }^{17}$ The nurses scored the CIRS directly after the data extraction.

A preliminary validation step obtained excellent inter-rater reliability after a standardization period (intraclass correlation coefficient: 0.91, 95\% confidence interval: 0.84-0.95). The CIRS generates a theoretical score ranging from 0 to 56 . The distribution of the scores is skewed to the left, however, because severe pathology in several systems inevitably leads to death. As there is no cutoff score above which one can conclude that multimorbidity is present, various cutoff points were used in this study.

\section{Statistical Analyses}

All the analyses were done using SPSS version 8 . The $\alpha$ significance level was set at 0.05 . The characteristics of the physicians who participated were compared with those of physicians who did not using Fisher's exact test or the Student $t$ test. The prevalence of multimorbidity is reported by age and sex. For the purpose of this report, we did not take into account the clustering of patients by physician. The very low intraclass correlation coefficient (0.03) justifies the analysis of morbidity at the patient level only. For the number of chronic conditions and the CIRS measure, both the mean and median were calculated. CIRS means were compared using a Kruskal-Wallis nonparametric test. Proportions were compared using the $\chi^{2}$ test. Finally, 95\% confidence intervals were also calculated.

\section{RESULTS}

Recruitment and data collection lasted from December 2002 to July 2003. Of the patients of the participating physicians, 1,085 were contacted. Of these, 980 (90.3\%) agreed to participate: 320 men and 660 women. The profile of the patients who refused to participate could not be determined. The number of patients per physician varied from 17 to 111 with a mean of 46.7. The average age of the patients was 58.2 years for men and 54.9 years for women. 
Most patients had multiple medical conditions (Figure 1). Nine of 10 had more than 1 chronic condition, and approximately $50 \%$ had 5 or more. As might be expected, the most common diagnoses were hypertension, hyperlipidemia, and rheumatologic diseases.

Table 3 shows the prevalence of multimorbidity in more detail, using various cutoff points for the number of problems and CIRS score. It shows clearly that the prevalence of multiple conditions increases with age, regardless of the cutoff point used. The frequency in women is higher than in men in the 45- to 64-year and 65-year and older age-groups; yet in most cases, there is some overlap in the confidence intervals. The 3 most common diagnoses did not differ in frequency between men and women.

The CIRS scores show no difference by sex for the 2

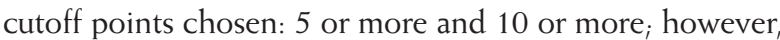
the proportion of patients with a high CIRS score rises with age in both men $(P<.001)$ and women $(P<.001)$.

Table 4 shows the mean and median number of health problems and CIRS scores by sex and age-group. Both of these variables increase with age in men $(P<.001)$ and women $(P<.001)$. A sex difference was found only in the number of conditions in the intermediate age-group.

\section{DISCUSSION}

We report the first Canadian prevalence data for multimorbidity in the adult population whose primary care is provided by family physicians. Given the lack of a clear definition of multimorbidity, different measures (num-

ber of health problems, CIRS

\section{Figure 1. Number of chronic health problems per patient} in the study population.

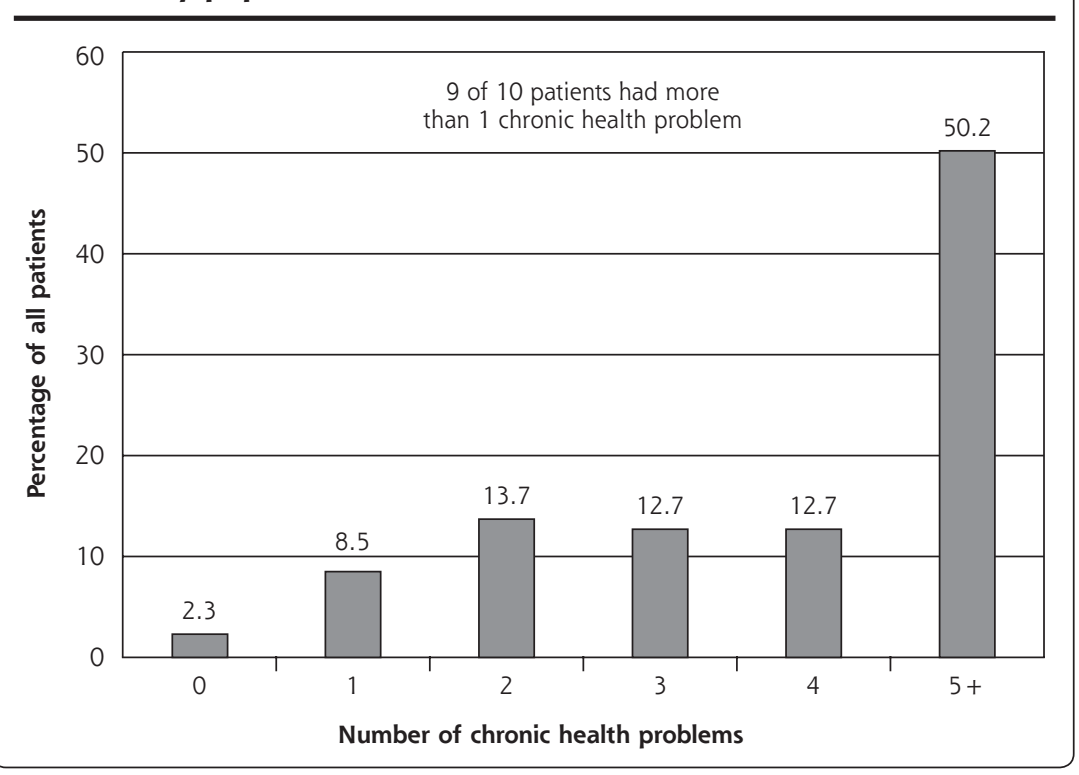

scores) and cutoff points were used to determine its prevalence.

Regardless of the definition used, this study confirms the increasing prevalence of multimorbidity with age in both men and women as documented in European $^{4,5}$ and American ${ }^{7-9}$ studies. The prevalences for individual age-groups obtained here, however, were much higher than those in other studies (Table 1). The number of chronic medical conditions (Table 3) is of particular concern. Nearly $50 \%$ of the patients between 45 and 64 years of age had 5 or more chronic conditions. We could not find any comparative data in the literature in which this cutoff point was used in other populations. Even so, we should

Table 3. Prevalence of Multimorbidity by Age and Sex

\begin{tabular}{|c|c|c|c|c|c|c|}
\hline \multirow[b]{3}{*}{ Index } & \multicolumn{6}{|c|}{ Percentage* of Patients With Multimorbidity $(95 \% \mathrm{CI})$} \\
\hline & \multicolumn{2}{|c|}{ 18-44 Years } & \multicolumn{2}{|c|}{ 45-64 Years } & \multicolumn{2}{|c|}{$65+$ Years } \\
\hline & $\begin{array}{c}\text { Male } \\
n=58\end{array}$ & $\begin{array}{c}\text { Female } \\
n=173\end{array}$ & $\begin{array}{c}\text { Male } \\
\mathrm{n}=141\end{array}$ & $\begin{array}{c}\text { Female } \\
n=288\end{array}$ & $\begin{array}{c}\text { Male } \\
n=121\end{array}$ & $\begin{array}{c}\text { Female } \\
n=199\end{array}$ \\
\hline \multicolumn{7}{|c|}{ Chronic health problems } \\
\hline 2 or more & $72(59-83)$ & $68(61-75)$ & $89(82-93)$ & 95 (92-97) & $98(93-99)$ & $99(97-100)$ \\
\hline 3 or more & $48(35-62)$ & $46(38-53)$ & $65(57-73)$ & $82(77-87)$ & $91(84-95)$ & $98(94-99)$ \\
\hline 4 or more & $38(26-52)$ & $30(23-37)$ & $52(43-60)$ & $66(60-71)$ & $83(75-89)$ & $91(86-94)$ \\
\hline 5 or more & $19(10-31)$ & $18(13-25)$ & $42(34-50)$ & $51(46-57)$ & $74(65-81)$ & $77(71-83)$ \\
\hline \multicolumn{7}{|l|}{ CIRS score } \\
\hline 5 or more & $55(42-68)$ & $48(40-56)$ & $80(73-86)$ & $85(80-89)$ & $93(87-97)$ & $98(94-99)$ \\
\hline 10 or more & $17(9-29)$ & $13(9-19)$ & $33(25-41)$ & $39(34-45)$ & $69(60-78)$ & $70(64-77)$ \\
\hline
\end{tabular}


Table 4. Number of Chronic Health Problems and CIRS Score by Age and Sex

\begin{tabular}{|c|c|c|c|c|c|c|}
\hline \multirow[b]{3}{*}{ Index } & \multicolumn{6}{|c|}{ Mean Multimorbidity Score $(95 \% \mathrm{Cl})$ [Median] } \\
\hline & \multicolumn{2}{|c|}{ 18-44 Years } & \multicolumn{2}{|c|}{ 45-64 Years } & \multicolumn{2}{|c|}{$65+$ Years } \\
\hline & $\begin{array}{c}\text { Male } \\
\mathrm{n}=58\end{array}$ & $\begin{array}{c}\text { Female } \\
\mathrm{n}=173\end{array}$ & $\begin{array}{c}\text { Male } \\
\mathrm{n}=141\end{array}$ & $\begin{array}{c}\text { Female } \\
n=288\end{array}$ & $\begin{array}{c}\text { Male } \\
\mathrm{n}=121\end{array}$ & $\begin{array}{c}\text { Female } \\
\mathrm{n}=199\end{array}$ \\
\hline $\begin{array}{l}\text { Number of chronic } \\
\text { health problems }\end{array}$ & $\begin{array}{c}2.9 \\
(2.4-3.4) \\
{[2.0]}\end{array}$ & $\begin{array}{c}2.7 \\
(2.4-3.0) \\
{[2.0]}\end{array}$ & $\begin{array}{c}4.1 \\
(3.66-4.45) \\
{[4.0]}\end{array}$ & $\begin{array}{c}4.8 \\
(4.5-5.1) \\
{[5.0]}\end{array}$ & $\begin{array}{c}6.3 \\
(5.8-6.8) \\
{[6.0]}\end{array}$ & $\begin{array}{c}6.6 \\
(6.21-6.92) \\
{[6.0]}\end{array}$ \\
\hline CIRS score & $\begin{array}{c}6.3 \\
(5.1-7.5) \\
{[5.0]}\end{array}$ & $\begin{array}{c}5.1 \\
(4.6-5.6) \\
{[4.0]}\end{array}$ & $\begin{array}{c}8.7 \\
(7.8-9.6) \\
{[7.0]}\end{array}$ & $\begin{array}{c}8.8 \\
(8.3-9.3) \\
{[8.0]}\end{array}$ & $\begin{array}{c}13.1 \\
(11.9-14.2) \\
{[12.0]}\end{array}$ & $\begin{array}{c}12.9 \\
(12.2-13.7) \\
{[12.0]}\end{array}$ \\
\hline
\end{tabular}

note that multimorbidity is often defined as 2 or more chronic diseases from a relatively short list of diagnoses. In our present study, we did not use a preestablished list; instead, we used all of the diagnoses found in the medical records, which resulted in a more comprehensive evaluation. Moreover, most of comparative data were collected in the 1990s or before. It is possible that some diagnoses (eg, hyperlipidemia, diabetes) have been more frequently reported in recent years as a result of some changes in diagnostic awareness.

As for the number of chronic problems per age-group, our data seem to be comparable to those obtained by Metsemakers et $\mathrm{al}^{5}$ in the Netherlands but much higher than those obtained by van den Akker et al ${ }^{4}$ in the Netherlands. This discrepancy raises a question about the quality of the data sources. Information about chronic medical conditions is more likely to be found in medical records than in other data sources, such as administrative data or surveys; therefore, a review of medical records seems to be a better way of estimating the prevalence of multimorbidity and may produce higher estimates.

Although the CIRS does not have a cutoff score to determine multimorbidity, the cutoff scores of 5 and 10 used in this study indicate disease in at least 2 or 3 systems and 4 or 5 systems, respectively. To illustrate what the burden-specific scores may represent, a patient with controlled hypertension, treated hyperlipidemia, and osteoarthritis would have a CIRS score of 5 (or a bit more). Adding a diagnosis like diabetes with renal involvement, along with heart disease and depression, would increase this score to 10 or even higher. A score 10 or higher seems adequate for discriminating between younger and older patients, and the high proportion of patients with such scores warrants more attention.

Another factor that could help explain the high prevalence of multimorbidity observed here is the relative lack of medical specialists in the Saguenay region. Some medical disciplines (eg, rheumatology) are not represented, whereas others (eg, nephrology, dermatology, gastroenterology) are represented by only a limited number of doctors. Thus, it is possible that some patients spill over into primary care practices. Nevertheless, the ratio of medical specialists in the Saguenay region (9 per 10,000 people) is similar to the Canadian average ${ }^{14}$ and midway between that of large urban centers and rural regions. This finding indicates that our results may be generalizable to the larger Canadian population.

Such a high prevalence of multiple chronic conditions calls into question the very organization of our health services. Any attempt at reengineering primary care should consider the high prevalence of multimorbidity. Interventions that suit patients with a single disease may not be appropriate for patients with many comorbid conditions. Practice guidelines would take advantage of addressing special recommendations for patients who have comorbid conditions, and clinical trials of drugs would improve external validity by including such patients. The results of this study offer additional support to the current trend in family medicine residency programs to concentrate on patients with multimorbidity.

Research efforts also must address an entity with such a high prevalence and potential impact. Theoretical and methodological aspects should not be neglected. The Chronic Care Model, ${ }^{20-22}$ used as a framework for the model described in the WHO report "Innovative Care for Chronic Conditions, ${ }^{16}$ may provide solid ground for developing such a research agenda. Persons with multimorbidity experience a wide range of barriers to self-care, including some that are specifically related to having multiple chronic conditions (eg, aggravation of one condition by the symptoms of or treatment of another). Barriers resulting from multimorbidity emphasize the importance of improved interventions and the development of new skills in the delivery of primary care. The wide extent of multimorbidity also strongly supports the development of innovative interventions focused on collaborative practices to better share the burden.

\section{Limitations}

Data obtained here are only estimates of the actual prevalence of multimorbidity in the population that consults family physicians. A random sample of each 
physician's patients would have been required to measure this prevalence more precisely. Our sample was probably overrepresented by patients who see their physicians often because of multiple conditions. That the practices were volunteer may also have introduced unknown biases. Moreover, the duration of doctorpatient relationship could not be controlled for because it was not recorded in this study.

Other factors that may reduce the generalizability of our results include the limited number of participating physicians, a female-to-male ratio exceeding that of the general population, and possible recruitment bias. For example, a physician's number of patients with multiple conditions may have influenced his or her likelihood of participating, generating a bias. Although physicians who agreed and refused to participate seemed comparable, few characteristics were compared. The use of exclusion criteria could also have led to a bias in patient recruitment. Even so, the consequences of excluding the small minority of patients who were pregnant, illiterate, or lacked decision-making capacity should have been negligible.

Another potential limitation of this study is that we did not assess patients' socioeconomic status. Low socioeconomic status has been associated with multiple chronic conditions, which could partly explain the high prevalence of multimorbidity observed. The socioeconomic status of Saguenay residents is, however, comparable to that of other Canadians.

This study sheds new light on the adult primary care population. Whether measured by the number of chronic conditions or CIRS scores, the prevalence of multimorbidity is high and increases significantly with age in both men and women. Patients with multimorbidity that are seen in family practice represent the rule rather than the exception. Given this high prevalence, clinicians, educators, researchers, and decision makers should review their priorities and pay special attention to the impact of multimorbidity. New health care models must be proposed and evaluated if we are to meet the needs of these patients.

To read or post commentaries in response to this article, see it online at http://www.annfammed.org/cgi/content/full/3/3/223.

Key words: Comorbidity; chronic disease; epidemiologic studies; family practice; prevalence

Submitted July 21, 2004; submitted, revised, November 12, 2004; accepted November 23, 2004

Funding support: Fonds de la Recherche en Santé du Québec (grant number 24300-2028) and Pfizer Canada (independent research grant).

\section{References}

1. van den Akker M, Buntinx F, Roos S, Knottnerus JA. Comorbidity or multimorbidity: what's in a name? A review of the literature. Eur J Gen Pract. 1996;2:65-70.
2. Fortin M, Lapointe L, Hudon C, Vanasse A. Multimorbidity in medical literature: Is it commonly researched? Can Fam Physician. 2005;51:244-245

3. Anderson GF. Partnership for solutions. Chronic Conditions: Making the Case for Ongoing Care. 2002. Robert Wood Johnson Foundation and John Hopkins University. Available at: http://www.partnershipforsolutions.org/. Accessed December 2003.

4. van den Akker M, Buntinx F, Metsemakers JF, Roos S, Knottnerus JA. Multimorbidity in general practice: prevalence, incidence, and determinants of co-occurring chronic and recurrent diseases. J Clin Epidemiol. 1998;51:367-375.

5. Metsemakers JFM, Höppener O, Knottnerus JA, Kocken RJJ, Limonard CBG. Computerized health information in the Netherlands: a registration network of family practices. Br J Gen Pract. 1992;42:102-106.

6. Fuchs Z, Blumstein T, Novikov I, et al. Morbidity, comorbidity, and their association with disability among community-dwelling oldest in Israel. J Gerontol A Biol Sci Med Sci. 1998;53A(6):M447-M455.

7. Wolff JL, Starfield B, Anderson G. Prevalence, expenditures, and complications of multiple chronic conditions in elderly. Arch Inter Med. 2002;162:2269-2276.

8. Guralnick JM, Lacroix AZ, Everett DF, Kovar MG. Aging in the eighties: the prevalence of comorbidity and its association with disability. Advance data from vital and health statistics; No. 170. Hyattsville, Md: National Center for Health Statistics; 1989. (Cited in Guralnick JM. Assessing the impact of comorbidity in the older population. Ann Epidemiol. 1996;6:376-380.)

9. Hoffman C, Rice D, Sung HY. Persons with chronic conditions: their prevalence and costs. JAMA. 1996;276:1473-1479.

10. Daveluy C, Pica L, Audet N, et al. Enquête Sociale et de Santé 1998. 2nd ed. Québec: Institut de la statistique du Québec; 2001.

11. Linn BS, Linn MW, Gurel L. Cumulative illness rating scale. J Amer Geriatr Soc. 1968;16:622-626.

12. De Groot V, Beckerman H, Lankhorst G, Bouter LM. How to measure comorbidity: a critical review of available methods. J Clin Epidemiol. 2003;56:221-229.

13. Harbourn M, Ankri J. Indices de comorbidité: revue de la littérature et application aux études des populations âgées. Rev Epidemiol Sante Publique. 2001;49:287-298.

14. Statistics Canada. Available at: http://www.statcan.ca. Accessed May 14, 2005.

15. Canadian Institute for Health Information. Available at: http://www. cihi.ca. Accessed May 14, 2005.

16. World Health Organization. Innovative Care for Chronic Conditions. Building blocks for action. Available at: http://www.who.int/chronic conditions/en/icccglobalreport.pdf. Accessed September 15, 2004.

17. Miller MD, Towers A. A Manual of Guidelines for Scoring the Cumulative Illness Rating Scale for Geriatrics (CIRS-G). Pittsburg, Pa: University of Pittsburgh; 1991.

18. Miller MD, Paradis CF, Houck PR, et al. Rating chronic medical illness burden in geropsychiatric practice and research: application of the cumulative illness rating scale. Psychiatry Res. 1992;41:237-248.

19. Hudon C, Fortin M, Vanasse A. Cumulative Illness Rating Scale was a reliable and valid index in a family practice context. J Clin Epidemiol. 2005;58:603-608

20. Bodenheimer T, Wagner EH, Grumbach K. Improving primary care for patients with chronic illness. JAMA. 2002;288:1775-1779.

21. Bodenheimer T, Wagner EH, Grumbach K. Improving primary care for patients with chronic illness: the chronic care model, Part 2. JAMA. 2002;288:1909-1914.

22. Wagner EH, Davis C, Scheafer J, Von Korff M, Austin B. A survey of leading chronic disease management programs: are they consistent with the literature? Managed Care Q. 1999;7:56-66.

23. Bayliss EA, Steiner JF, Fernald DH, Crane LA, Main DS. Descriptions of barriers to self-care by persons with comorbid chronic diseases. Ann Fam Med. 2003;1:15-21. 